\title{
Id, Ego dan Superego Dalam Pendidikan Islam
}

\section{Husin, M.Pd.}

Email. hafizhihusinsungkar@gmail.com

( Dosen Tetap Prodi PGMI STIQ Amuntai )

Psikologi lahir sebagai disiplin ilmu tersendiri di Jerman pada pertengahan abad ke XIX. Sebagai suatu ilmu, psikologi merupakan ilmu yang relatif muda apabila dibandingkan dengan ilmu-ilmu yang lain. Terkait dengan tentang kepribadian dalam psikologi, pandangan Sigmund Freud tentang Id, Ego dan Superego telah mempengaruhi manusia sepanjang abad ke XX. Dalam kajian Islam, teori tentang Id, Ego dan Superego bukanlah hal baru. Pembahasan tentang nafs, al- 'aql dan al-qalb yang merupakan kajian tentang struktur kepribadian manusia telah Allah SWT. paparkan dalam Al-Quran yang secara meyakinkan menjadi "induk" dari ilmu-ilmu yang datang kemudian.

Kata Kunci: Id, Ego, Superego, Pendidikan Islam

\section{A. Pendahuluan}

Manusia adalah makhluk yang unik. Dalam perjalanan hidupnya manusia tidak hanya menjadi subyek dalam segala hal, akan tetapi sekaligus menjadi objek dari apa yang dihasilkan. Di sini kita dapati dua kenyataan tentang seorang manusia. pertama, dia adalah satu diri yang berbeda dari yang lain (unik). Kedua, terlihat melalui perilaku setiap orang yang seringkali tampak memiliki persamaan atau kesamaan dengan orang lain.

Manusia terlahir memiliki fisik yang sama, akan tetapi dalam perkembangan selanjutnya memiliki kepribadian yang mungkin hampir sama ataupun berbeda dengan yang lainnya. Kepribadian berasal dari kata pribadi yang berarti orang seorang alias se (satu ) diri, dan kemudian pada kata se diri itu disisipi huruf $n$, sehingga menjadi sendiri. Orang Inggis menyebut kepribadian dengan istilah personality, berasal dari kata person, yang juga berarti orang (manusia) seorang. Begitu juga dalam bahasa Arab menyebut kepribadian dengan istilah

Jurnal Ilmiah Al QALAM, Vol. 11, No. 23, Januari-Juni 2017 
Syakhsyiyyah, dari kata syakhsun, yang berarti orang seorang pula. Dalam bahasa Indonesia ada istilah lain yang cukup memberikan gambaran dari arti kepribadian yaitu jati diri, yang berarti keadaan diri (sendiri) yang sebenarnya (sejati).

Dalam konsep kepribadian manusia, Sigmund Freud mengemukakan teorinya tentang kepribadian manusia menjadi tiga bagian, yaitu id, Ego dan Superego. Ketiga komponen tersebut merupakan kesatuan proses psikologis yang tidak dapat dipisahkan satu dengan yang lainnya. Jika dianalogikan bahwa id adalah komponen biologis, Ego adalah komponen psikologis dan Superego adalah komponen sosial.

\section{B. Biografi Sigmund Freud}

Sigmund Freud yang dikenal sebagai bapak Psikoanalisis itu lahir di Freiberg, Moravia pada tanggal 6 Mei 1856 dan beliau meninggal pada tanggal 23 September 1939 di London. Freud hampir 80 tahun tinggal di kota Wina dan dia meninggalkan kota itu ketika Nazi menaklukan Austria. Freud memasuki fakultas kedokteran Universitas Wina pada tahun 1873 karena mengejar cita-citanya untuk menjadi ahli ilmu pengetahuan dan tamat pada tahun 1881. Setelah meluluskan kuliahnya sebenarnya freud tidak berkeinginan untuk membuka praktik sebagai dokter, tetapi karena keadaan yang memaksa maka dia melakukan praktik. Selama ia melakukan praktik ia mendapatkan kepuasan karena memiliki kesempatan untuk melakukan research dan menulis, sehingga jiwa penyelidiknya tersalurkan.

Ketika masih menjadi mahasiswa kedokteran, Freud membangun hubungan professional dan pribadi yang erat dengan Josef Breuer, dokter terkenal asal Wina yang berusia empat belas tahun lebih 
tua dari Freud, dan memiliki tingkat keilmuan yang layak diperhitungkan. Breuer lah yang mengajarkan katarsis pada Freud, yaitu proses menghilangkan histeria dengan cara "mengungkapkannya", sembari menggunakan kataris, Freud secara bertahap dan penuh keuletan menemukan teknik asosiasi bebas, yang segera menggantikan hypnosis sebagai teknik terapeutik utamanya.

Akan tetapi kedua ahli tersebut bertentangan pendapat mengenai pentingnya faktor seksual dalam histeria. Freud berpendapat bahwa konflik-konflik seksual merupakan sebab dari histeria sedangkan Breuer dalam hal ini berpandangan lain. Sejak perpisahan dengan Breuer itu Freud, menempuh jalannya sendiri dan mengemukakan gagasan-gagasanya yang merupakan dasar dari teori psikoanalisis dan memuncak dengan terbitnya karya utamanya yang pertama “traumdeutung" (Tabir mimpi, The Interpretation of Dream, 1900) ${ }^{1}$.

Setelah perpisahannya dengan Breuer itu juga Freud menjadi semakin akrab dengan Wilhelm Fliess, dokter asal Berlin yang berperan memperkuat gagasan-gagasan barunya Freud. Surat-surat yang ditulis Freud kepada Fliess menjadi sebuah bukti yang merekam lahirnya psikoanalisis dan tumbuhnya embrio teori Freud.

Freud juga sempat menganalisis dirinya sendiri dengan proses yang penuh pergulatan sepanjang hidup. Selama itu Freud memandang dirinya sebagai pasien yang paling baik, dengan bukti surat yang ditulisnya kepada Fliess, "Perhatian saya tersita oleh pasien saya yang paling penting yaitu diri saya sediri”... Analisis itu ternyata lebih sulit

1 Sumadi Suryabrata,Psikologi Kepribadian, (Jakarta : PT RajaGrafindo Persada, 2008) hal. 123

Jurnal Ilmiah Al QALAM, Vol. 11, No. 23, Januari-Juni 2017 
dibanding yang lain, karena itulah yang melumpuhkan kekuatan psikisnya.

Buku-buku serta tulisannya yang lain segera menjadi pusat perhatian para ahli diseluruh dunia. Freudpun diikuti oleh Ernest Jones dari Inggris, Carl Gustav Jung dari Zurich, A.A. Brill daro New York, Sandor Jerenzi dari Budapest, Karl Abraham dari Berlin dan Alfred Adler dari Wina. Dua diantara pengikutnya itu kemudian memisahkan diri dari Freud karena pendapat yang berbeda, mereka itu adalah : A. Adler (mendirikan Individual Pscychologie pada tahnun 1910) dan C.G. Jung (mendirikan Analiytische Pscychologie pada tahun 1913).

\section{C.Id, Ego dan Superego}

1. Id (Das Es)

Id adalah suatu kata yang sangat dominan dikenal dengan prinsip kesenangan (Pleasure Principle) karena selalu berusaha meredam ketegangan dengan kepuasan. Id adalah salah satu komponen yang hadir sejak lahir. Untuk menghilangkan ketidak enakan atau ketegangan itu dan mencapai kenikmatan maka Id mempunyai dua macam, yaitu : (1) refleks dan reaksi otomatis, seperti misalnya bersin, berkedip dan sebagainya. (2) Pross primer, seperti misalnya orang yang lapar membayangkan makanan.

Singkatnya $I d$ adalah wilayah yang primitive, kacau balau yang tak terjangkau oleh alam sadar. Id tidak sudi diubah, amoral, tidak logis, tak bisa diatur dan penuh energi yang datang dari 
dorongan-dorongan dasar serta dicurahkan semata-mata untuk memuaskan prinsip kesenangan ${ }^{2}$.

Menurut definisi yang ada maka dapat kita pahami bahwa Id itu adalah perasaan naluriah yang ada sejak manusia lahir yang perasaan itu jika di lakukan atau direalitakan maka prinsip kesenangannya akan tersalurkan. Contohnya saja seperti orang yang merasakan lapar dan haus ia pasti berpikir untuk makan. Seperti bayi yang merasakan lapar ia akan menangis jika tuntutan Id -nya tidak terpenuhi.

Akan tetapi jika $I d$ itu ada namun tidak ada yang memperantarai $I d$ untuk menjadi kenyataan maka $I d$ tidak akan menuju kepada kepuasan. Itu adalah sistem lain yang menghubungkan dengan dunia obyektif atau realita. Sistem yang menjadi penghubung itu adalah Ego (Das ich).

\section{Ego (Das Ich)}

Ego o adalah suatu sistem yang bereaksi dengan proses sekunder, proses sekunder adalah merupakan proses berpikir yang realistis karena Ego memang dikendalikan oleh prinsip kenyataan. Ego inilah yang bertugas untuk merencanakan apakah Id akan dilakukan atau bahkan diabaikan saja. Ego merupakan sistem yang menjadi penengah antara Id dan Super Ego, jadi dengan kata lain Ego adalah merupakan perancang atau perencana yang yang mengontrol segala tindakan yang dilakukan manusia.

Ego (aku sadar), yang berfungsi untuk meredakan ketegangan dalam diri dengan cara melakukan aktivitas

${ }^{2}$ Jess Feist, GrEgory J Feist, Theories of Personality, (NY, 1221 Avenue Of the American, 2009) diterjemahkan oleh Hadriatno dengan judul Teori Kepribadian, hal. 32 .

Jurnal Ilmiah Al QALAM, Vol. 11, No. 23, Januari-Juni 2017 
penyesuaian dorongan-dorongan yang ada dengan kenyataan objektif (realitas). Ego memiliki kesadaran untuk menyelaraskan dorongan yang baik dan buruk hingga tidak terjadi kegelisahan atau ketegangan batin ${ }^{3}$.

Ego dapat pula dipandang sebagai aspek eksplisif kepribadian oleh karena Ego ini mengontrol jalan-jalan yang ditempuh, memilih kebutuhan-kebutuhan yang dapat dipenuhi dan cara-cara memenuhinya, serta memiliki obyek yang dapat memenuhi kebutuhan. Di dalam menjalankan fungsi ini sering kali Ego harus mempersatukan pertentangan antara Id dan Super Ego serta dunia luar. Namun haruslah selalu diingat bahwa Ego adalah derivate dari Id dan bukan untuk merintanginya. Peran utamanya adalah menjadi perantara antara kebutuhan-kebutuhan instinktif dengan keadaan lingkungan demi kepentingan adanya organisme ${ }^{4}$.

Sebagai contoh, ketika anak belajar dengan terbiasa diberikan imbalan atau penghargaan dari orang tua, maka merekapun akan berpikir untuk melakukan apa yang seharusnya mereka lakukan supaya mereka mendapatkan hadiah kembali dan tidak mendapatkan hukuman.

Dari contoh diatas sangat jelas Ego itu adalah sistem yang berfungsi untuk memikirkan tindakan yang akan dilakukan supaya kenikmatanlah yang akan menjadi hasil. Belajar memikirkan apa yang harus dan tidak dilakukan, inilah yang menjadi bibit atau asal-usul Superego.

\section{Super Ego} 208.

${ }^{3}$ Jalaluddin,Psikologi Agama (Jakarta : PT RajaGrafindo Persada, 2008) hal.

${ }^{4}$ Sumadi Suryabrata,Psikologi Kepribadian... hal.127.

Jurnal Ilmiah Al QALAM, Vol. 11, No. 23, Januari-Juni 2017 
Dalam psikologi Freudian, Superego atau saya yang lebih (abive-I), mewakili aspek-aspek moral dan ideal dari kepribadian serta dikendalikan oleh prinsip-prinsip moralitas dan idealis yang berbeda dengan prinsip kesenangan dari id dan prinsip realistis dari Ego. Superego berkembang dari Ego dan Superego, ia tidak punya sumber energinya sendiri akan tetapi Superego berbeda dari Ego dalam satu hal penting, Superego tidak punya kontak dengan dunia luar sehingga tuntutan Superego akan kesempurnaanpun menjadi tidak realistis ${ }^{5}$.

Superego berisikan dua hal, yaitu : Conscienta yang berarti menghukum orang dengan memberikan rasa dosa dan Ego ideal yang menghadiahi seseorang dengan rasa bangga akan dirinya.

Untuk mudahnya Superego bisa kita pahami sebagai perwujudan internal dari nilai-nilai dan cita-cita tradisional masyarakat sebagaimana yang telah diajarkan orang tua kepada anaknya dengan cara memberikan hadiah atau hukuman. Superego selalu menuntut kepada kesempurnaan dari apa yang telah diajarkan kepadanya mekipun terkadang kesempurnaan itu tidak sejalan dengan keadaan yang nyata.

Superego dipergunakan untuk menyempurnakan dan membudayakan perilaku manusia. Maksudnya segala perilaku manusia itu akan dibuat untuk supaya tidak melanggar normanorma, adat, serta budaya yang ada di masyarakat. Superego akan memberikan penilaian dan melakukan pilihan benar salah, baik buruk bermoral atau tidak. Pilihan ini adalah merupakan solusi bagi Ego dalam memberikan keputusan atas tuntutan id.

${ }^{5}$ Jess Feist, GrEgory J Feist, Theories Of Personality ... hal. 34.

Jurnal Ilmiah Al QALAM, Vol. 11, No. 23, Januari-Juni 2017 
Fungsi-fungsi pokok Superego :

a. Merintangi impuls-impuls $I d$, terutama impuls-impuls seksual dan agresif.

b. Mendorong Ego untuk memberikan tujuan-tujuan realistis dengan tujuan-tujuan moralistis.

c. Mengejar kesempurnaan.

D. Ayat Al-Quran Yang Menggambarkan Adanya Id, Ego dan Superego

Dalam Q.S. Yusuf / 12:23 Allah berfirman :
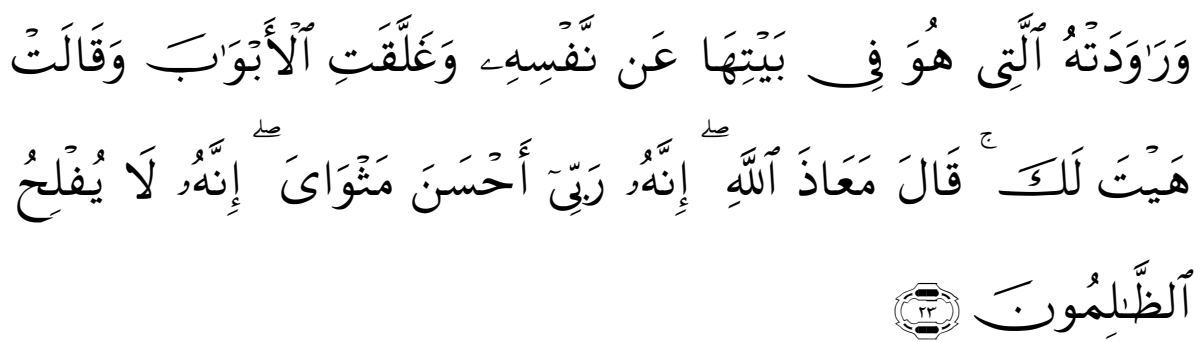

Artinya : "Dan wanita yang dia (Yusuf) tinggal dirumahnya menggodanya untuk menundukkan dirinya (kepadanya) dan dia menutup pintu rapat-rapat, seraya berkata, "marilah kesini, aku untukmu” Yusuf berkata, “perlindungan Allah sungguh, Dia Tuhanku, Dia telah memperlakukan aku dengan baik. Sesungguhnya orang-orang yang zalim tidak akan beruntung".

Demikian Yusuf menyebutkan tiga hal setelah tiga hal pula yang dilakukan oleh wanita itu : merayu, menutup rapat-rapat pintu, dan mengajak berbuat berbuat sesutau yang keji. Dijawab oleh Yusuf dengan memohon perlindungan Allah, mengingat anugerah Allah SWT antara lain melalui jasa-jasa suami wanita itu serta menggaris bawahi 
bahwa ajakan itu adalah kezaliman, sedang orang-orang zalim tidak pernah beruntung.

Dari ayat tersebut kita ketahui bahwa Nabi Yusuf menggunakan ketiga teori yang digagas oleh Freud. Sebagai manusia Nabi Yusuf pasti memiliki nafsu (Id) untuk ajakan Zulaikha tetapi karena hati (Superego)nya juga terdidik dan berfungsi maka akal (Ego)nya menolak ajakan Zulaikha. Disinilah fungsi dari akal dan hati yang terdidik, hatinya sangat menentang perbuatan tersebut karena ia mengetahui bahwa orang-orang yang zalim itu tidak akan beruntung, kemudian akalnyalah yang memikirkan bagaimana ia akan menentang ajakan tersebut.

Dalam ayat selanjutnya dalam surah Q.S.Yusuf / 12:24 Allah berfirman :

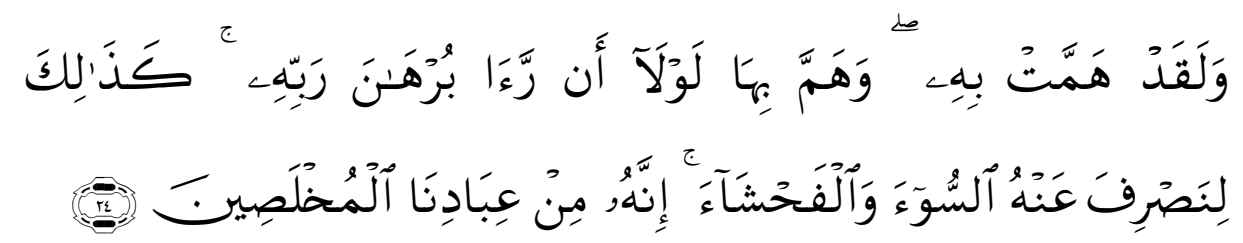

Artinya: "sungguh wanita itu telah bermaksud dengannya dan diapun telah bermaksud dengannya andaikata dia tidak melihat bukti Tuhannya. Demikianlah, agar kami memalingkan darina kemungkaran dan kekejian.Sesungguhnya dia termasuk hamba-hamba kami yang terpilih".

Banyak sekali faktor lahiriah yang seharusnya mengantar Nabi Yusuf as. menerima ajakan wanita itu. Dia seorang pemuda yang belum menikah yang mengajaknya adalah seorang wanita cantik lagi berkuasa. Kebaikan wanita itu terhadap Yusuf as. pasti sangat banyak, dan perintahnya sebelum peristiwa ini dan juga sesudahnya selalu diikuti Yusuf. Wanita itu sudah pasti berhias dan memakai wewangian, suasana istana pasti nyaman. Pintu-pintu pun telah ditutup rapat, gorden 
dan tabirpun telah ditarik, rayuan dilakukan berkali-kali bahkan dengan tipu daya sampai dengan memaksa yang mengakibatkan bajunya sobek. Boleh jadi Yusuf as. yang mengetahui seluk beluk rumah dan kepribadian wanita itu tahu bahwa kalaupun ternyata ketahuan oleh suaminya, maka sang istri yang disayanginya itu akan dapat mengelak. Apalagi suaminya amat cinta kepadanya, namun sekali lagi semua faktor pendukung terjadinya kedurhakaan tidak mengantar Yusuf untuk tunduk dibawah nafsu dan rayuan $\operatorname{setan}^{6}$.

Dari penjelasan diatas dapat pula kita simpulkan bahwa Nabi Yusuf sekali lagi menolak ajakan Zulaikha dengan hal yang sudah di dirancang dan dipikirkan supaya tingkah lakunya tidak menyalahi norma dan aturan yang ada. Nafsu (id)nya dapat ditahan karena akal (Ego)nya mempertimbangkan apa yang ada dalam hati (Superego)nya.

\section{E. Teori Sigmund Freud dalam Islam dan Hubungannya dalam Pendidikan Islam}

1. Nafsu (Id)

Dalam Kamus Besar Bahasa Indonesia nafsu itu berarti keinginan (kecenderungan, dorongan) hati yang kuat. Dorongan yang kuat untuk berbuat kurang baik. Jadi nafsu itu cenderung mengantarkan manusia kepada hal tercela.

Diri atau nafs memiliki pemaknaan kata yang banyak. Menurut Mubarok, (2002:27)nafs memiliki arti (1) jiwa, (2) dorongan hati yang kuat untuk berbuat kurang baik, (3) perilaku yang melahirkan sifat tercela dan perilaku buruk, (4) sesuatu didalam diri manusia yang menggerakan tingkah laku dan (5) sisi dalam manusia yang dicipta secara sempurna dimana didalamnya

\footnotetext{
${ }^{6}$ Quraish shihab,Tafsir Al-Misbah (Jakarta : Penerbit Lentera Hati, 2002) hal. 428.
}

Jurnal Ilmiah Al QALAM, Vol. 11, No. 23, Januari-Juni 2017 
terkandung potensi yang baik dan buruk. Dari sekian pengertian tersebut dapat digaris bawahi nafs (jiwa) memiliki dua kecenderungan yaitu : (1) baik dan buruk, (2) dorongan dan tingkah laku ${ }^{7}$.

Menurut Imam Syafi'I, nafs adalah lathifah rabbaniyah, yaitu roh sebelum bersatu (ta'alluq) dengan jasad. Nafs tersebut dibagi tujuh bagian, yaitu :

a. An-Nafs Ammarah, yaitu nafs yang condong kearah tabi'at badaniyah dan menyeru kepada kenikmatan (al-ladzat) dan syahwat yang terlarang oleh syariat.

b. An-Nafs al-Lawwamah, yaitu nafs yang mendapat cahaya dari qalb kemudian kadang-kadang mengikuti kekuatan akal dan terkadang menyimpang sehingga membuatnya menyesal. Ia adalah sumber penyesalan (manba' an-nadamah) karena merupakan awal munculnya hawa nafsu. Firman Allah SWT dalam Q.S Yusuf / 12:53 sebagai berikut :

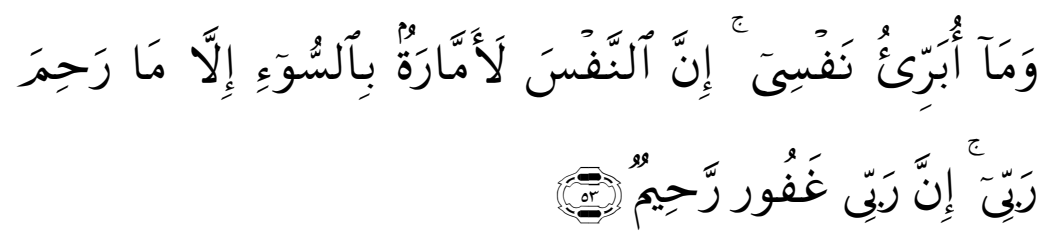

Artinya : "Sesungguhnya nafsu itu selalu menyerukan pada perbuatan buruk, kecuali nafsu yang diberi rahmat oleh Tuhanku."

c. An-Nafs al-Muthmainnah, yaitu nafs yang mendapat cahaya dari qalb dan terbebas dari sifat-sifat yang hina.

${ }^{7}$ Rafi sapuri,Psikologi Islam (Jakarta : Rajawali Pers, 2009) hal. 43.

Jurnal Ilmiah Al QALAM, Vol. 11, No. 23, Januari-Juni 2017 
d. An-Nafs al-Mulahhimah, yaitu nafs yang pendapat ilham berupa ilmu, ketawadhu'an, qana'ah dan kemurahan (sakhawah). Ia adalah sumber kesabaran dan syukur.

e. An-Nafs ar-Radhiyah, yaitu nafs yang ridha kepada Allah SWT dan tempat (sya'an)nya adalah keselamatan.

f. An-Nafs al-Mardhiyah, yaitu nafs yang diridhai oleh Allah SWT dan bekasnya berupa karomah, ikhlas dan zikir.

g. An-Nafs al-Kamilah, yaitu nafs yang telah sempurna secara tabiat (thab'an) dan perangai (syajiyyatan).

Nafsu pada hakikatnya memiliki dua kekuatan, yaitu ghadabiyah yaitu kekuatan yang berusaha menghindarkan manusia dari sifat tercela, dalam artian nafsu yang satu ini adalah sistem yang melindungi Ego dari kesalahan, sedangkan kekuatan yang kedua adalah Al-Syahwat yang berarti daya yang berpotensi untuk mengarahkan Ego kepada hal yang menyenangkan.

Di atas telah dijelaskan bahwa nafsu itu adalah sumber dari segala kejelekan. Apabila manusia dikuasai oleh nafsu dan melayani semua dorongan dari nafsu maka hawa nafsu dalam dirinyalah yang akan menguat. Jika nafsu yang ada dalam diri manusia itu telah menguat maka dirinya akan tumbuh menjadi orang yang zalim, seperti yang disebutkan dalam Al-Quran Q.S.Rum / 30:29 Allah Berfirman :

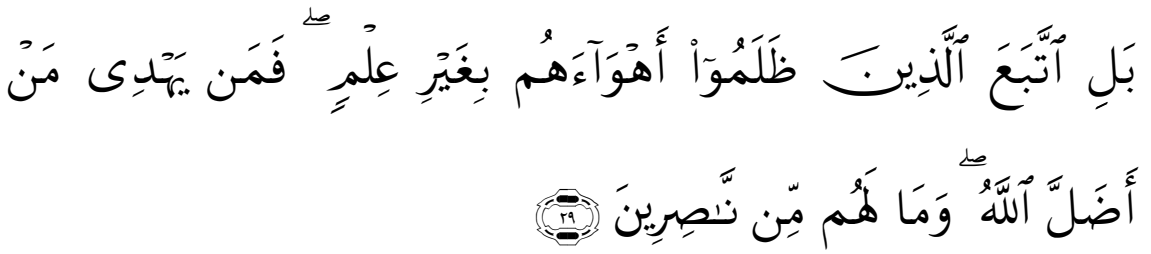

Jurnal Ilmiah Al QALAM, Vol. 11, No. 23, Januari-Juni 2017 
Artinya : "tetapi orang-orang yang zalim mengikuti hawa nafsunya tanpa ilmu pengetahuan".

Dalam ayat tersebut dapat kita pahami bahwa seseorang akan bisa mengendalikan nafsunya dengan ilmu. Pada dasarnya manusia memang diperintahkan untuk mencari ilmu, karena ilmu akan membuat manusia menjalani hidup sesuai dengan apa yang sewajarnya ia jalani.

Ilmu agamalah yang seharusnya diakuasai oleh manusia karena agama telah mengatur segalanya dengan baik, termasuk mengatur pada saat seperti apa nafsu seorang manusia dapat disalurkan agar mereka tidak melanggar budaya serta norma yang ada dalam agama.

2. Akal (Ego).

Akal dalam Kamus Besar Bahasa Indonesia diartikan daya fikir (untuk memahami sesuatu dan sebagainya), pikiran, ingatan.

Akal manusia, menurut Imam al-Ghazali sangat beragam dan dapat dikelompokkan atas : Akal praktis (al-'amilat) dan akal teoritis (al-'alimat). Sedangkan berdasarkan tinggi jangkauannya dapat dibedakan atas : akal material (al-'aql-hayulani), akal mungkin (al-'aql al-malakat), akal aktual (al-'aql bi al-fi'il) dan akal perolehan (al-'aql al-mustafad). Akan tetapi, ternyata kemampuan ini ada batasnya diatas akal ada ilham yang dimensinya lebih tinggi dan mendekati hakikat. Setelah tenggelam dalam tasawuf, Imam Al-Ghazali membagi akal menjadi akal (berpikir dan belajar) dan taklid (mengikuti) kepada $\mathrm{Nabi}^{8}$.

${ }^{8}$ Rafi Sapuri,Psikologi Islam... hal. 49

Jurnal Ilmiah Al QALAM, Vol. 11, No. 23, Januari-Juni 2017 
Akal dapat berfungsi dengan baik apabila didukung oleh pendengaran, penglihatan dan hati sebagai alat yang membantu akal untuk bisa berfungsi sesuai dengan apa yang seharusnya ia lakukan.

Kekuatan akal dapat kita simpulkan menjadi dua yaitu akal yang terinderai (rasio nafsani) dan akal yang tak terinderai (rasio qalbani). Contoh dari rasio nafsani adalah ketika kita melihat sesuatu maka yang terekam adalah pemanfaatannya, ketika mendengar sesuatu maka yang terbayang adalah baik buruknya dan ketika merasa maka yang dialami adalah kesenangan dan ketidaksenangan. Rasio nafsani ini dapat ditingkatkan dengan membaca, buku diskusi, menulis dan lainnya yang berhubungan dengan penambahan pemikiran dan pengayaan wawasan.

Sedangkan kekuatan rasio qalbani adalah pemikiran yang mampu menembus alam metafisik, bahkan kekuatan ini tetap aktif disaat manusia tidur. Contoh dari kekuatan ini adalah ketika melihat maka makna dari apa yang dilihatnya itu adalah keagungan Tuhan. Ketika mendengar, maka yang terekam adalah nasihat dan pelajaran dan ketika manusia merasa maka yang dirasakannya adalah kasih sayang Tuhan. Kekuatan ini dapat ditingkatkan dengan memperbanyak zikir, I'tiqaf, muhasabah, berpuasa, membaca al-quran dan mengamalkan amalan sunnah.

Jadi akal ini adalah proses menuju kepada pintu tingkah laku, artinya segala tingkah laku yang dilakukan manusia itu akallah yang terlebih dahulu merencanakan, merancang perbuatan apa yang harus ia lakukan dan bagaimana ia melakukannya. 
Jika akal itu sudah terdidik dengan ajaran Islam maka segala perilaku yang dilakukannya pasti didasari dengan aturanaturan agama yang telah ia ketahui. Pendidikan agama sangatlah berpengaruh terhadap akal, agar akal dapat merencanakan dengan baik perilaku manusia dan tidak melenceng dari aturan agama.

\section{Qalb (Superego)}

Qalb adalah hati yang menurut istilah kata (terminologis) artinya sesuatu yang berbolak-balik, berasal dari kata qalaba, artinya membolak-balikkan. Qalb bisa diartikan hati sebagai daging sekepal (biologis) dan juga bisa berarti kehatian (nafsiologis) ${ }^{9}$.

Dari pengertian tersebut dapat kita pahami bahwa hati adalah sebuah sistem yang tidak tetap dan kadang berubah dari waktu kewaktu. Ada sebuah hadits Nabi riwayat Bukhari Muslim berbunyi sebagai berikut :

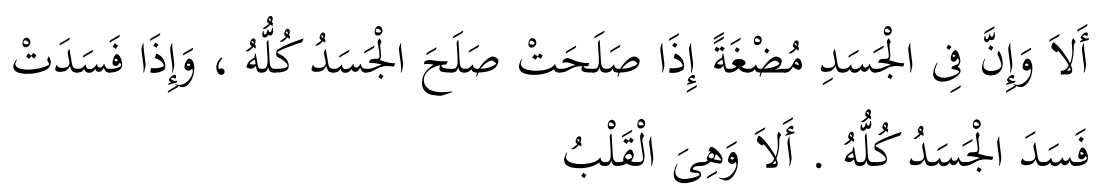

Artinya: "ketahuilah bahwa di dalam tubuh ada sekepal daging. Kalau itu baik, baiklah seluruh tubuh. Kalau itu rusak, rusaklah seluruh tubuh. Itulah Qalb". ${ }^{10}$

Dari hadits tersebut dapat kita simpulkan bahwa seorang manusia itu dikendalikan oleh hati. Jika hati manusia itu terdidik

\footnotetext{
${ }^{9}$ Jalaluddin,Psikologi Agama ...... hal. 205.

${ }^{10}$ (HR. Bukhari no. 52 dan Muslim no. 1599). Syarh Al Bukhari, Ibnu Batthol, Asy Syamilah
}

Jurnal Ilmiah Al QALAM, Vol. 11, No. 23, Januari-Juni 2017 
dengan baik maka perilakunya akan mengikuti didikan yang telah ada dalam hatinya.

Dengan demikian, Qalb adalah sebagian dari spiritual manusia. Ia ada tapi keberadaannya hanya dapat dirasakan seperti tiupan angin yang semilir terasa menyejukkan. Untuk dapat merasakannya dibutuhkan seni tersendiri yaitu menghaluskan segala gerak dan daya, baik dengan berzikir, I'tiqaf, muhasabah, shalat atau dapat juga melalui meditasi dengan memusatkan perhatian pada sentuhan-sentuhan kasih sayang Allah. Sebagaimana halnya bagian fisik, Qalb juga memiliki kebutuhan, antara lain : ketenangan, kedamaian, keterancaman, keindahan dan cinta, gerakan qalb amat halus, lembut tapi memiliki kekuatan yang tak terbendung oleh apapun ${ }^{11}$.

Hati bisa dikatakan sebagai hati yang hidup apabila hati itu memiliki pengetahuan. Dengan pengetahuan tersebut hati bisa bekerja mengikuti aturan-aturan dari pengetahuannya tersebut. Disinilah pentingnya pendidikan jika hati seseorang telah terdidik dengan keIslaman, dan kebudayaan maka hati akan mengontrol tingkah laku untuk selalu berbuat baik dan mengejar kesempurnaan dalam beribadah kepada Allah SWT.

\section{F. Simpulan}

Id (nafsu)adalah sifat naluriah yang ada pada setiap manusia. Id ini juga dikenal dengan prinsip kesenangan, karena selalu berusaha meredam ketegangan dengan kepuasan. Ketika $I d$ ini disalurkan atau direalitakan maka prinsip kesenangan akan tersalurkan.

\footnotetext{
${ }^{11}$ Rafi saputi,Psikologi Islam... hal. 161.
}

Jurnal Ilmiah Al QALAM, Vol. 11, No. 23, Januari-Juni 2017 
Ego (akal), adalah suatu sistem yang berfungsi untuk memproses bagaimana cara merealitakan id. Ego adalah sistem yang menjadi penengah antara Id dan Superego, Ego adalah alam perencana dengan mempertimbangkan hal-hal yang bersumber dari $I d$ dan Superego. Ego merupakan sistem yang realita dan Ego juga dikenal dengan prinsip realitas.

Superego (hati) adalah sistem yang dikenal dengan prinsip kesempurnaan. Karena Superego ini yang mengarahkan Ego untuk mempertimbangkan nilai-nilai, norma dan budaya seperti apa yang telah diajarkan kepadanya.

Ketiga komponen ini sangat mempengaruhi tingkah laku manusia dan sangat menentukan apa yang harus dilakukan manusia ketika nafsunya telah mendesak dan ingin segera disalurkan.

Dalam Pendidikan Islam, nafsu akan dapat di"puas"kan ke arah yang seharusnya apabila Aql dan Qalb dididik dan diarahkan sesuai dengan tuntunan Al-Quran dan Hadits. Aql dan Qalb seseorang yang telah terdidik dengan nilai-nilai keIslaman, maka hati akan mengontrol tingkah laku untuk selalu berbuat baik dan mengejar kesempurnaan dalam beribadah kepada Allah SWT. 


\section{DAFTAR PUSTAKA}

Feist Jess, GrEgory J Feist, Theories Of Personality. NY. 1221 Avenue Of theAmerican, Diterjemahkan oleh Handriatno dengan judul Teori kepribadian. 2009.

Gulen Fethullah, Memadukan Akal dan Kalbu dalam Beriman. Jakarta. PT Raja Grafindo Persada. 2002.

Jalaluddin, Psikologi agama. Jakarta. PT Raja Grafindo Persada. 2008.

Shihab Quraish, Tafsir Al-Mishbah. Jakarta. Penerbit Lentera Hati. 2002.

Sapuri Rafy, Psikologi Islam. Jakarta. Rajawali Pers. 2009.

Suryabrata Sumadi, Psikologi Kepribadian. Jakarta. PT Raja Grafindo Persada. 2008.

Syarh Al Bukhari. Maktabah Asy Syamilah. 